\title{
Sujeitos e objetos do sucesso: antropologia do Brasil emergente*
}

\author{
Karen Polaz**
}

\begin{abstract}
O emergente é hoje um símbolo do sucesso. Não importa de onde você veio - de Cascadura ou de Bonsucesso, importa onde você está. Não adianta vir da Suíça e ir sabe Deus aonde - melhor nem citar o nome do lugar. O importante é estar bem com seu sucesso. Os conceitos sobre emergência mudaram muito. O importante agora é ser qualificado como 'produtivo', seja você tradicional ou emergente. Se você é tradicional e não produz, não será nada. Da mesma forma, se você é emergente, não pode parar de emergir!
\end{abstract}

A citação acima, proferida por Vera Loyola (p.25) ou a "primeira-dama da Sociedade Emergente da Barra da Tijuca", contém os elementos que sintetizam e lançam luz sobre as questões que despertaram o interesse de Diana Lima em estudar esses novos segmentos da "elite" do Rio de Janeiro, os "emergentes" da Barra que, através do enriquecimento advindo de investimentos na esfera mercantil, vêm consolidando uma identidade própria e fincando novos critérios classificatórios na sociedade brasileira. Com esse estudo de caso, a autora busca evidenciar representações mais gerais sobre a estrutura social do país.

* Resenha de LimA, Diana N. O. Sujeitos e objetos do sucesso: antropologia do Brasil emergente. Rio de Janeiro, Garamond, 2008, 242p. Recebida para publicação em agosto de 2010, aceita em setembro de 2010.

**Mestranda do grupo FOCUS na Faculdade de Educação da UNICAMP karenpolaz@yahoo.com.br

cadernos pagu (35), julho-dezembro de 2010:389-398. 
Sujeitos e objetos do sucesso: antropologia do Brasil emergente

Em Sujeitos e Objetos do Sucesso, livro integrante da Coleção Cultura e Economia da Editora Garamond, Lima foca sua atenção no consumo de bens e serviços por esses ditos "emergentes" da Barra e, principalmente, no que se diz sobre esse consumo, observando os discursos perpetrados com frequência e insistência cotidiana no jornalismo social entre 1994 e 2000. Essas falas, "fofocas", comentários, produzidos a partir da mídia e difundidos para além da sociedade carioca, conformaram um fato social particular e, portanto, um objeto de grande importância interpretativa para a autora.

Lima observou que os "emergentes", em plena ascensão social e econômica, triunfavam nos espaços menos "sérios" da mídia como indivíduos de sucesso, enquanto a "classe média" aparecia como um segmento prejudicado pela comentada "crise econômica" da década de 80, perante o boom de consumo iniciado em 1980 e estendido pelos anos 90. As trajetórias de "sucesso" dos "emergentes" eram vistas, por esse tipo de mídia, como decorrência do trabalho árduo e braçal em seus negócios originalmente de pequeno porte. Esses indivíduos gozavam, portanto, de uma posição tida como "vitoriosa" na sociedade brasileira e correspondiam às expectativas de um país que, finalmente, rumava para um lugar de glória no capitalismo mundial.

A "abertura dos mercados" na década de 1990, característica de um momento recente de transição na história político-econômica do Brasil, quando a economia se voltava para a competitividade, permitiu o pujante enriquecimento de alguns estratos sociais. Nesse quadro, segundo Lima, o jornalismo social pôde criar e articular todo um sistema discursivo, a partir de notícias e imagens, que associa indivíduos com trajetórias de "sucesso" ao consumo de bens de alto custo, valorizando o binômio trabalho árduo/êxito material e sustentando, simbolicamente, tal recurso classificatório.

Ao abordar o consumo pela via antropológica, Lima inscreve seu trabalho na perspectiva iniciada por Douglas $e$ 
Isherwood (1979) de construir uma ponte entre Antropologia e Economia. Foi mais precisamente a partir desse clássico que a antropologia do consumo pôde reunir contribuições importantes $e$ expandir o debate de maneira a tentar suprimir os preconceitos e intolerâncias históricas quanto ao consumo nas análises científicas. Para Lima, até o final da década de 1970, os estudos sobre consumo realizados pelas ciências sociais produziam discursos enraizados em pressupostos $e$ verdades bastante conformes às falas de algumas colunas sociais e do senso comum de forma geral.

No primeiro capítulo, ao discutir o sub-tema "Os objetos na vida social", Lima traz para a análise Os argonautas do Pacífico ocidental (1922), de Malinowski, e o Ensaio sobre a dádiva (1924), de Marcel Mauss, obra de grande influência para $O$ mundo dos bens. Num momento inspirador do livro, a autora segue relacionando, a partir da noção de "sistemas de troca", o "kula", o "potlatch" e o consumo moderno, para assim poder analisar a notícia de uma festa de 1994, em que o colunismo social "diagnostica" certa "disputa" pelo posto de "elite" no interior da sociedade carioca. Lima demonstra que o texto dessa notícia descreve um "potlatch", "um verdadeiro ritual de dispêndio por parte desses sujeitos sociais que desejariam o posto de "nova elite" (p.74).

Nessa notícia, os objetos estão presentes como "marcadores públicos de categorias sociais", no sentido cunhado por Douglas e Isherwood. Para os autores, e Lima inscreve sua análise nessa perspectiva, os bens em si são completamente arbitrários, ou seja, não é inteligível separar os objetos uns dos outros para observação. É preciso, antes, percebê-los como partes de um sistema de significação, cujo sentido social apenas se dá na relação entre eles. Do mesmo modo, não se pode explicar o consumo sem entender os padrões de cultura e de usos dos bens, usos estes que estão informando o conjunto de valores vigentes na sociedade. Se os bens não podem ser tomados isoladamente, torna-se incoerente, para a análise antropológica, a distinção entre 
Sujeitos e objetos do sucesso: antropologia do Brasil emergente

necessidade e "luxo", visto que a função essencial do consumo consiste na capacidade para dar sentido à vida coletiva. Os autores promovem, assim, uma espécie de "desmitificação" do "luxo" com intuito de abolir tal distinção.

Convencida de que o consumo é uma área de investigação antropológica legítima, para além das acusações de que sua categoria empírica é alvo, devido a seus usos materiais, a autora procurou compreender esse novo estrato social, os "emergentes", percebendo-os como

uma fala saturada de valor e operada no interior dessa sociedade que, além de ter lido com voracidade sobre seu estilo de vida, incorporou as categorias do jornalismo social que o ocasionou para pensar sobre si, para viver transformações e, dependendo das circunstâncias e círculos, então, marcar alteridades e firmar identidades (p.52).

Sem perder de vista que os grupos sociais falam de si e entre si de acordo com o que consomem, Lima aponta a necessidade de capturar as preferências de consumo, contextualizá-las $e$ interpretar os significados aí contidos. Explicita, outrossim, o intuito de registrar seu estudo no contexto das pesquisas etnográficas que atentam para a dialética entre sujeitos e objetos modernos.

Com limites, é possível comparar o Rio de Janeiro a Winston Parva, nome fictício de uma pequena comunidade da Inglaterra, estudada no final dos anos 1950 por Norbert Elias e John L. Scotson em Os Estabelecidos e os Outsiders, outra referência marcante no trabalho de Lima. Os autores procuraram compreender como um grupo de moradores se julgava imensamente superior a um outro grupo, já que não havia, entre eles, diferenças de nacionalidade, etnia, tipo de ocupação, nível educacional, classe social - em suma, não se diferenciavam em nada, apenas pelo tempo de residência no lugar. O grupo de moradores mais antigos via as novas famílias de maneira 
Karen Polaz

depreciativa, chegando a estigmatizá-las, a considerá-las de "menor valor humano", fazendo, até certo ponto, com que os recentes moradores se sentissem, realmente, inferiores. $\mathrm{O}$ tempo mais longo de residência foi fundamental para a coesão grupal entre os estabelecidos e para a produção de uma identidade em comum, conhecida e compartilhada entre esses indivíduos, que se valiam da "fofoca" como um eficaz mecanismo de controle social.

Ao modo de Elias e Scotson, Lima também problematizou processos de classificação, hierarquização e discriminação social no Rio de Janeiro, a princípio, identificando, por meio do estudo do jornalismo social, "disputas" pela posição de "elite" entre "emergentes" e outros membros da classe alta carioca, os "tradicionais". O termo criado pela mídia em 1994, a "Nova Sociedade Emergente" da Barra da Tijuca ("gente desconhecida, porém endinheirada") vinha se contrapor à "Tradicional Sociedade Carioca" da Zona Sul, em franca decadência financeira, mas ainda percebida como a "bem-nascida", detentora da "cultura legítima", do "gosto", da "elegância" e da "distinção" em termos bourdieusianos.

No decorrer do livro, Lima vai demonstrando, todavia, que essa oposição não se sustenta. A autora, carioca advinda da Zona Sul, pensava os "emergentes", inicialmente, como um "outro" distante a ser descoberto, mas se surpreendeu ao perceber que sua própria rede de relações sociais $e$ a de seus pesquisados partilhavam mais semelhanças do que diferenças. Sem sofrer nenhum "choque" ao longo do convívio no campo, o trabalho empírico sugeriu-lhe ir observando e comparando as "elites" da Zona Sul e da Zona Oeste, o "aqui" e o "ali". A posição de pesquisadora em estado etnográfico num terreno e rede de relações sociais a ela familiares acabou por sujeitá-la a uma constante vigilância epistemológica.

Chama atenção a clareza com que Lima explicitou sua pesquisa de campo e sua preocupação invariável em praticar uma antropologia do consumo séria, desconstruindo, por meio da experiência in loco, quaisquer expectativas - até mesmo 
Sujeitos e objetos do sucesso: antropologia do Brasil emergente

preconceitos - anteriores. Não por acaso, reconhece terem sido corriqueiras as falas, entre sujeitos das camadas médias e altas da Zona Sul, que incorporaram os discursos da mídia e olhavam os "emergentes" com desconfiança, mas cujas escolhas simbólicas não diferiam tanto daquelas realizadas por esses novos segmentos de "elite". Em geral, muitos indivíduos têm consumido bens, inclusive "bens de luxo", e frequentado, cada vez mais, clínicas de estética e academias de ginástica.

Se os "emergentes" eram vistos ora como "bem-sucedidos" ora com zombaria e deboche por seus (maus) usos materiais, Lima não sentiu, por parte deles, vergonha da própria origem ou desejo de se assemelhar à suposta "elite tradicional". Da mesma maneira, não pareciam preocupados em se "distinguir" dos "tradicionais", firmando critérios de "gosto" próprio. Sem negar as peculiaridades no interior de cada grupo, $e$ não os homogeneizando, Lima observou certo exagero nas diferenças proclamadas pela mídia e difundidas pela sociedade carioca, pois não encontrou uma fronteira identitária nítida entre os emergentes $e$ os estabelecidos. Aqui se torna evidente a importância da etnografia para a antropologia; ir a campo, conviver com os "nativos" e, no caso de Lima, ouvir diretamente os "emergentes", e não apenas ouvir sobre os "emergentes", de forma a abranger todos os discursos.

Principal expoente do glamour system brasileiro, a revista Caras, como bem observado por Lima, estampa tipos sociais que, independente de sua origem sociogeográfica e socioeconômica heterogênea, conquistaram, recentemente ou não, por meio de perseverança e trabalho duro e exaustivo, uma posição privilegiada na sociedade brasileira. São ilustrados, sempre sorridentes, em momentos de festas e comemorações, de lazer, em mansões cinematográficas, vestindo roupas caras, exibindo carros importados, ou seja, apresentando-se como sujeitos que obtiveram prestígio e status social. Ao serem assim retratados, em momentos de "glória" e em meio à coleção de conquistas materiais, seu "sucesso" é publicamente evidenciado e 
reconhecido. Desse modo, teria sido interessante que Lima, além de descrever as imagens das revistas, também as tivesse reproduzido em seu livro, visto que o sistema discursivo articulado por essa revista enfatiza a imagem do "sucesso" em detrimento do texto, além de se tratar de sujeitos nacionalmente conhecidos.

Talvez concentrados dentre os "emergentes", os sinais de consumo conspícuo, tantas vezes alardeados pela mídia, resultavam antes de seu poder aquisitivo do que de sua ascensão social, "gosto" ou qualquer regime de valores que os especificariam. Isso fica claro a partir do início dos anos 2000, quando o jornalismo social começa a empregar outros termos que não a oposição "tradicionais"/"emergentes", nomenclatura em vigência por 10 anos na mídia ${ }^{1}$, articulando em torno da noção de glamour a reunião de sujeitos "produtivos", que reverenciam o dinheiro merecidamente conquistado. Na revista Caras, essas fronteiras identitárias entre os segmentos da "elite" se tornam, portanto, ainda mais obscuras, criando a impressão, no leitor, de que ela é uma só. Atenção particular deve ser dada ao quarto e último capítulo - "A emergência de um fenômeno brasileiro" -, no qual Lima procura desenvolver uma inteligibilidade mais ampla sobre a sociedade brasileira, pensando juntamente, e não poderia ser de outro modo, os dois momentos constitutivos da economia de mercado: produção e consumo.

Tão forte é o discurso que valoriza a "produtividade" que nem todos os pesquisados atribuíam a si mesmos o adjetivo de "emergentes", por entenderem que são, antes, sujeitos com "trajetórias de sucesso", e "sucesso" enquanto sinônimo de crescimento financeiro. A fala constante sobre seu empreendedorismo autônomo, seus "negócios", seu "suor" e sua condição de "batalhadores" não está situada apenas na Barra e perpassa classes sociais. Mesmo em famílias pertencentes à "elite" por várias gerações, o dinheiro vem sendo o critério primordial

${ }^{1}$ Lima afirma que, entre a sociedade carioca, essa oposição e todo o discurso condenatório de que os "emergentes" são "exibidos" e "querem aparecer" ainda havia continuado e, por isso, demandaria investigação. 
Sujeitos e objetos do sucesso: antropologia do Brasil emergente

para a escolha profissional e sua valorização constitui um fenômeno visto no Brasil inteiro.

Outro aspecto interessante e bem observado pela autora é que, em vez do cultivo de si (Bildung) como meio histórico de acesso à distinção, os "emergentes" consideram "sucesso" o retorno financeiro alcançado através de seu esforço e trabalho árduo, e que esse estilo de vida, no qual há valorização do acúmulo material, perpetua-se através das gerações. Assim, o capital cultural, dentre a "elite" brasileira, não tem sido a marca de distinção social por excelência, mas, sim, o êxito financeiro, conformando um fato socialmente produzido pela recente história do país. A sensibilidade estética, portanto, não pode ser um parâmetro nítido para diferenciar os segmentos dessa "elite" no Brasil, como aconteceu na França dos anos 1960 e 1970 estudada por Bourdieu.

Essa explicação e compreensão mais ampla do consumo em seu formato moderno na sociedade brasileira permitiu que Lima chegasse a seu argumento central: nesse processo de identificação social, em grande parte articulado e positivado pela própria mídia, existe um ethos que valoriza, simultaneamente, o trabalho árduo $e$ o consumo conspícuo. A autora sugere que esse desejo por bens de alto custo, bens estes fabricados material e simbolicamente pelo capitalismo e tão característico dos "emergentes", ultrapassa as fronteiras da Barra da Tijuca e pode ser verificado em diferentes meios sociais e são valorizados em toda parte. Ao positivar a equação trabalho + dinheiro $=$ sucesso, a mídia privilegia os "vencedores" do mercado, sendo o ethos emergente um valor social consagrado pelo nosso tempo.

Uma crítica que considero pertinente ao trabalho de Lima diz respeito ao tratamento dado à questão de gênero, talvez insuficientemente abordada em sua explicação, ainda mais num estudo que busca, através de um caso particular, compreender aspectos mais amplos sobre a estrutura social do país. Embora não fosse o foco da pesquisa, a questão de gênero deveria ter sido constitutiva do próprio recorte feito pela autora, que chega a 
afirmar que o estereótipo do "emergente" é a mulher dita "perua", que faz uso constante de recursos da medicina estética e consome bens de alto custo. No senso comum, as "peruas" estão associadas ao excesso, ao mau gosto e, mais importante para análise, à futilidade ${ }^{2}$, tendo em Vera Loyola um conhecido expoente.

Tomando a noção de gênero, não em uma dimensão empírica, mas como um recurso classificatório, acredito que repousa nas mulheres um eixo explicativo importante para $\mathrm{o}$ fenômeno discutido no livro, que contribuiria para refletir sobre o sentido e a implicação desse processo de classificação social que relaciona mais mulheres do que homens ao glamour system. A elas que se "incumbe a divulgação da imagem de bem sucedido, mais que a seus maridos" (p. 220), atuando, em grande parte, como "empresárias morais", pois na maior parte do tempo seus maridos "estão ou muito envolvidos no suor do trabalho, ou muito envolvidos num certo segredo da própria atividade" (p. 220). Além disso, Lima informa que, em 2003, a revista Caras atraía 3.875.000 leitores, dos quais $69 \%$ mulheres.

Considero que isso não seja uma justificativa ou explicação, mas um fator a ser investigado, a ser continuamente problematizado pela análise antropológica. Lamento que Lima tenha dedicado não mais que duas páginas ao assunto, pois, na dinâmica da produção das identidades nas sociedades modernas, não há como desconsiderar a relação de dominação masculina $e$ esse caso teria sido bastante apropriado para discutir parte de um imaginário do senso comum que, no caso dos "emergentes", associa a maioria das mulheres a uma imagem negativa do "consumismo", a espaços midiáticos menos "sérios" e à futilidade, em oposição a homens "batalhadores", que "não têm tempo para isso".

\footnotetext{
${ }^{2}$ Lima observa que havia menções constantes ao trabalho árduo, visto como um valor para os "emergentes" e mesmo para esse segmento da mídia, mas não mobilizava tanto o senso comum quanto a "ostentação" e a "futilidade", que constituíam um afronte à moralidade tão arraigada no mundo cristão.
} 
Sujeitos e objetos do sucesso: antropologia do Brasil emergente

Uma lição a ser extraída do livro, e de outros clássicos das ciências sociais aqui citados, é que não se pode avaliar qualquer fenômeno como um conjunto independente, separado, isolado de práticas, símbolos e sentidos, desconsiderando sua relação com o todo. Ao ter levantado uma bibliografia que não relega nenhuma fonte importante para a discussão que pretendeu fazer e com uma experiência etnográfica consistente, Lima pôde contribuir para um melhor entendimento do consumo moderno e dos processos de estratificação social e composição das "elites" no Brasil da última década do século XX e início do XXI. Além disso, como lembra Luiz Fernando Dias Duarte, o foco "emergente", num país de mudanças rápidas, possibilita abranger múltiplos sinais contemporâneos que não são apenas apanágios das "elites". Não por acaso, a autora dedica-se, atualmente, à pesquisa dos fiéis da Igreja Universal do Reino de Deus, com o escopo principal "de compreender sua adesão à promessa de prosperidade e salvação no mundo". 3

\section{Referências bibliográficas}

DOUGLAS, Mary \& ISHERWOOD, Baron. O Mundo dos Bens: para uma antropologia do Consumo. Rio de Janeiro, Editora UFRJ, 2009.

ELIAS, Norbert \& SCOTSON, John L. Os estabelecidos e os outsiders. Rio de Janeiro, Jorge Zahar, 2000.

LiMA, Diana N. O. Ethos "emergente": as pessoas, as palavras e as coisas. Horizontes antropológicos, vol. 13, $\mathrm{n}^{\circ}$ 28, Porto Alegre, jul./dez., 2007, pp.175-202.

\footnotetext{
${ }^{3}$ Trecho retirado do perfil da autora no site do IUPERJ: http://www.iuperj.br/. Acesso em junho de 2010.
} 